\title{
PRELIMINARY FINDINGS OF A VIRTUAL REALITY APP FOR CHILDREN WITH SPECIAL NEEDS
}

\author{
Danijel Bjelic and Thomas Keller \\ ZHAW, Switzerland
}

\begin{abstract}
Immersive Virtual Reality (VR) is slowly finding its way into classrooms as an alternative form of experience and action-oriented learning. Generally VR shows a value-added for topics that either are too far away to visit, too small to touch, to dangerous or expensive to manipulate or simply virtual. This range of application is potentially extended for children with special needs or complex disorders. One reason may be that our world is simply too complex for them and hence jeopardizes their health. But often people simply are too stressed to take some extra time to take care in the daily routine. Therefore, a value added for an immersive VR learning unit may simply be a realistic model of a public place like a train station where these children can exercise and practice their skills, e.g., finding places. Together with a foundation for children with special needs, their therapists and teachers, and five children a learning unit playing at a train station was evaluated as a pilot regarding usability and acceptance amongst all concerned stakeholders. Although only a very limited number of participants were involved the pilot application showed potential for further development in this very special context.
\end{abstract}

\section{KEYWORDS}

Virtual Reality, Children with Complex Disorders

\section{INTRODUCTION}

(Hattie et al., 2017) showed that digitization plays a major role in learning. It is also stated that digitization has an effect size of 0.57 for children with special needs. Any value above 0.4 is considered more effective than the effect of ordinary school attendance. VR as a digital form of experiential and action-oriented learning in (Swiss) elementary schools is currently still in its infancy. Commercially available learning units that can be conducted via fully immersive head-mounted displays are hardly available today. There is no established procedure model for creating a VR lesson and measuring the effect. However, usability tests at elementary schools have shown that the use of VR is considered promising by teachers. In addition, there is a high acceptance among the children. In field experiments three prototypically developed VR learning units were tested (Keller et al., 2018) (Keller et al., 2019).

The use of virtual environments for children with complex disabilities is as diverse as the field of complex disabilities itself and the people it serves. People with special needs often have problems with attention, language, spatial perception, memory, higher reasoning, and knowledge acquisition (Cai et al., 2017). Research on the use of virtual learning environments targets both cognition and behavior (Jeffs, 2010). Back in 2011, Parsons and Cobb published an article on the state-of-the-art of VR technologies for children with autism spectrum disorder. Newer studies were performed by (Bradley \& Newbutt, 2018) and . In it, they state that there is unique potential for the use of the technology. However, the features of VR must be used in a way that best supports the learning process (Parsons \& Cobb, 2011). In 2018, a Systematic Review based on empirical studies was conducted on the topic of autism and VR head-mounted displays. The conclusion stated that there is a contradiction in this area of research. This is because research around head-mounted displays proposes user immersion in a computer-generated environment that represents and reflects real-world features and activities, but rarely conducts real-world verification (Bradley \& Newbutt, 2018). Thus, in this work, during the evaluation phase, this gap in previous research will be addressed and real-world verification will be conducted. 


\section{OBJECTIVE}

The work is carried out in cooperation with a Foundation for children with special needs. The foundation describes itself as a learning and living space and, in addition to residential groups and a wide range of therapies, also offers a school. There, the children and young people are taught basic skills for different stages of life.

The aim of the research work is the development of a virtual reality learning unit especially for children with complex disabilities. Whereby the focus is on the improvement of independence and orientation in the real world. The learning unit is intended to provide supplementary support for traditional teaching. The main part of the work consists of the development and the preceding conception of a prototype for the use case around challenges at a train station. The aim here is to create a representation of the world that is as real as possible without overwhelming the children.

\section{THE USE OF VIRTUAL REALITY FOR CHILDREN WITH SPECIAL NEEDS}

Hollenweger \& Bühler define complex disabilities as follows: "Complex disability involves an intelligence disorder (ICD-10: F70-F73) or a profound developmental disorder (ICD-10: F84) (Classification of Diseases $(I C D)$, n.d.). According to ICD-11, complex disability is newly understood as a neurodevelopmental disorder and defined as a "disorder of intellectual development" (Disorder of Intellectual Development, 6A00). This may occur in combination with other disorders (e.g., Autism Spectrum Disorder (ASD)), diseases (Fragile X Syndrome in relation to protein formation), or impairments in bodily functions (e.g., visual or auditory functions, movement-related functions)." (Hollenweger \& Bühler, 2019)

VR learning units allow researchers and educators to study and assess student behavior while maintaining control over the stimuli generated. In doing so, there is the opportunity to adjust the complexity of a learning task and specifically measure learning performance (Bozgeyikli et al., 2017). In the future, the use of VR may complement or even replace traditional assessment tools and methods for diagnosis (VrSocial, 2018). There are numerous scientific papers that propose, demonstrate and validate the use of VR for children with special needs, very often in the scope of Autism Spectrum Disorder (ASD), e.g.,virtual travel training (Simões et al., 2018), social-emotional stories (Ghanouni et al., 2019). Most VR applications to date for children with complex disabilities are found in the areas of social skills, anxiety management, mobility, mathematics, science, or (sign) language. There are also combinations of these areas (Ip et al., 2018).

In a research on the selection and development characteristics of a virtual learning environment, navigation and interaction were investigated. It was found that navigation is one of the most difficult tasks for people with learning disabilities. Therefore, it was important that the input devices be compatible with the performance of the learning task (Lannen et al., 2002). Hands-on learning activities provided within a virtual learning environment are beneficial for individuals with learning disabilities to practice and acquire new skills (Cromby et al., 1996).

People with ASD often have difficulties with social interactions, verbal and nonverbal communication, and cognitive tasks, such as contextualization, impulse control, inhibitions, or other behaviors (WHO, n.d.). One study examined multimedia interfaces for users with high-functioning autism. It was found that richer multimedia learning interfaces do not add value to facilitate learning for people with autism. In fact, simple interfaces work best for these individuals (Grynszpan et al., 2008).

Various studies (Cobb, 2007), (Self et al., 2007), (Parsons, 2000), (Herrera et al., 2006) confirm that people with ASD can adapt skills they have acquired using virtual realities to the real world.

In a recent research from Ukraine, children with ASD were taught basic traffic rules as pedestrians using VR and machine learning (ML). The VR provides a game-like environment and a controllable avatar that represents the student. The ML portion of the system is responsible for adjusting the response of the environment based on the student's behavior. It was found that the children were more socialized after the learning session. However, it had to be noted that it also took explanations from the children' parents and caregivers for the understanding about certain situations to be achieved. (Horbova et al., 2020). 


\section{THE PROTOTYPE}

The prototype includes a model of the Lucerne train station. Following Figure 1 gives an impression of the quality of the model. The prototype was developed with Unreal and has been tested and used with an HTC Vive.

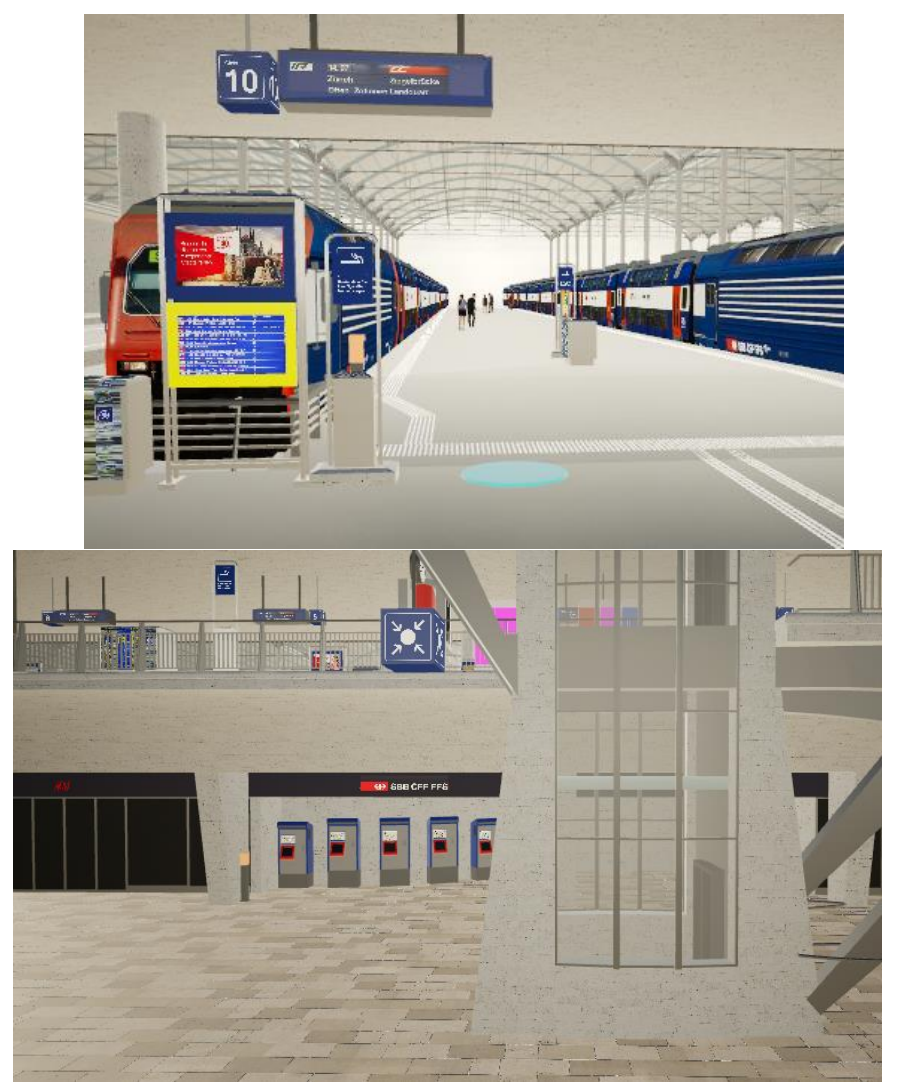

Figure 1. An impression of the quality of the model of the train station Lucerne

Learning unit 1 starts in the basement of the Lucerne train station. In front of the user, there is a large light blue cylinder on the floor that activates the first task. If the student walks into this cylinder, the task of finding the toilets follows via the audio channel. If the student finds the toilets and steps into the next light blue cylinder, the task is acoustically confirmed as successfully completed and the next task is announced. The next task is to find the retailer Coop. In front of the Coop there is again a blue cylinder which, when it overlaps with the student, announces the next and last task of this learning unit. The last task is about finding the meeting point. This task is also no longer marked with a blue cylinder. Once the meeting point has been found, the session ends and the End level is started.

Learning unit 2 starts in front of the platforms. In front of the user is a large light blue cylinder which activates the first task. This tells the student to go to platform 10. In front of platform 10 is the next cylinder. The next cylinder confirms the completion of the first task and announces the next one. The student has to board the train at the right place. The task is completed when the student is in front of the first passenger door of the train at track 10. As in session 1, the session is ended and the End level is started.

\section{THE FIELD EXPERIMENT}

The field experiment included three phases:

- The first phase consisted of an excursion to a real train station. Most of the children would use this station if they were more independent. There, the children were successively given the same or similar tasks as 
subsequently in the learning units. In the process, they were filmed with a video camera.

- The second phase consisted of the application of the VR learning unit, which took place over two weeks. The children went through the tasks a total of five times.

- Finally, the third phase consisted of another field trip to a different train station to qualitatively observe the children's progress and to determine whether the VR learning units had an effect on the children' behavior in the real world. The children were again given the same or similar tasks as in the learning unit. They were also filmed with a video camera during the second visit.

A total of five children and their respective caregivers participated in the complete field experiment. Unfortunately, a larger number of children was not possible due to the current circumstances.

Generally it is claimed that the highest possible degree of immersion should be aimed for and that, optimally, all possible stimuli should be generated by the VR system. This is contrasted with the findings from studies of individuals with complex disabilities, which claim that too many stimuli are counterproductive. It was interesting to see that some of the children were severely overwhelmed with the mental challenge of being in a virtual world, seeing it, being a part of it, and at the same time paying attention to the auditory stimuli of the learning task. Omitting the headphones and using only one controller eliminated some VR-generated stimuli from the learning session. However, this allowed the children to cope better with the new situation.

It is unclear whether an increase in VR-generated stimuli would have been justifiable with longer engagement with the learning units. It would be helpful if different levels of stimulus generation could be parameterized. This would allow the learning unit to accommodate each student's current stimulus tolerance. The multiplayer approach could also provide interesting insights. For example, several children could enter a virtual environment together with their teachers and leave the announcement of the learning task to the teacher.

When selecting the use case, it has proven useful to follow the finding of Dalgarno and Lee (2010) and use VR where a real situation is difficult to depict and perform in the real world. Also relevant seems to be the verification of what is learned in the real world. Bradley and Newbutt (2018) criticized in their systematic review that often verification is not done. To be able to verify the impact of the learning units, the two visits to the train stations were particularly important. Learning is also a social process and children with complex disabilities in particular often struggle to show what they have learned or are underappreciated by society. Therefore, real-world verification is an important element in the approach.

\section{CONCLUSION}

The children enjoyed learning with the VR learning units and were highly motivated. Whether the motivation and enthusiasm of the children can be maintained over a longer period of time will be seen in the following months. All children would like to continue learning with a VR offering in the future. This was to be expected, as it was a positive change from traditional teaching. For many of the children, it was also their first exposure to a fully immersive VR system. A clear benefit for children is the controlled environment provided by VR. This allows unwanted situations to be avoided. The children can build up their skills in a protected setting without fear of the unexpected. Whether this leads to a negative effect in the long term, in the sense of a blunting against possible dangers, could not be recognized in this short duration.

The implementation of the learning units also aroused the interest of other teachers and supervisors who were not directly involved in the project. The few who had put on the headset were convinced of the technology's potential. Some were already talking about future use cases, such as traffic training. Others saw potential opportunities for other input devices and their use, such as eye tracking control, which is already in use in some cases for children with wheelchairs.

\section{REFERENCES}

Booth, A., Sutton, A., \& Papaioannou, D. (2016). Systematic Approaches to a Successful Literature Review. SAGE.

Bozgeyikli, L., Raij, A., Katkoori, S., \& Alqasemi, R. (2017). A survey on virtual reality for individuals with autism spectrum disorder: Design considerations. IEEE Transactions on Learning Technologies, 11(2), 133-151.

Bradley, R., \& Newbutt, N. (2018). Autism and virtual reality head-mounted displays: A state of the art systematic review. 16. 
Cai, Y., Chiew, R., Nay, Z. T., Indhumathi, C., \& Huang, L. (2017). Design and development of VR learning environments for children with ASD. Interactive Learning Environments, 25(8), 1098-1109. https://doi.org/10.1080/10494820.2017.1282877

Classification of Diseases (ICD). (n.d.). Retrieved May 28, 2021, from https://www.who.int/standards/classifications/classification-of-diseases

Cobb, S. V. G. (2007). Virtual Environments Supporting Learning and Communication in Special Needs Education. Topics in Language Disorders, 27(3), 211-225. https://doi.org/10.1097/01.TLD.0000285356.95426.3b

Cromby, Standen, \& Brown. (1996). The potentials of virtual environments in the education and training of people with learning disabilities. https://doi.org/10.1046/j.1365-2788.1996.805805.x

Dalgarno, B., \& Lee, M. J. W. (2010). What are the learning affordances of 3-D virtual environments? 17.

Ghanouni, P., Jarus, T., Zwicker, J. G., Lucyshyn, J., Mow, K., \& Ledingham, A. (2019). Social Stories for Children with Autism Spectrum Disorder: Validating the Content of a Virtual Reality Program. Journal of Autism and Developmental Disorders, 49(2), 660-668. https://doi.org/10.1007/s10803-018-3737-0

Grynszpan, O., Martin, J.-C., \& Nadel, J. (2008). Multimedia interfaces for users with high functioning autism: An empirical investigation. International Journal of Human-Computer Studies, 66(8), 628-639. https://doi.org/10.1016/j.ijhcs.2008.04.001

Hattie, J., Zierer, K., \& Beywl, W. (2017). Lernen Sichtbar Machen Für Lehrpersonen. Überarbeitete Deutschsprachige Ausgabe (3. Unveränderte Auflage). Schneider Verlag Hohengehren GmbH.

Herrera, G., Jordan, R., \& Veraa, L. (2006). Abstract concept and imagination teaching through Virtual Reality in people with Autism Spectrum Disorders. http://dx.doi.org/10.3233/TAD-2006-18403

Hevner, A., March, S. T., Park, J., \& Ram, S. (2004). Design science in information systems research. MIS Quarterly, 28 (1), 75-105.

Hollenweger \& Bühler. (2019). 20190611_Anwendung des LP21 für SuS mit komplexen Behinderungen.pdf. https://www.regionalkonferenzen.ch/sites/default/files/inlinefiles/20190611_Anwendung\%20des\%20LP21\%20f\%C3\%BCr\%20SuS\%20mit\%20komplexen\%20Behinderungen.p df

Horbova, M., Andrunyk, V., \& Chyrun, L. (2020). Virtual Reality Platform Using ML for Teaching Children with Special Needs. 12.

Ip, H. H., Wong, S. W., Chan, D. F., Byrne, J., Li, C., Yuan, V. S., Lau, K. S., \& Wong, J. Y. (2018). Enhance emotional and social adaptation skills for children with autism spectrum disorder: A virtual reality enabled approach. Computers \& Education, 117, 1-15.

Jeffs, T. L. (2010). Virtual Reality and Special Needs. 16.

Keller, T., Hagen, F., \& Brucker-Kley, E. (2019). A field study about the impact of a VR learning unit. 307-314. https://digitalcollection.zhaw.ch/handle/11475/18788

Keller, T., Hebeisen, A., \& Brucker-Kley, E. (2018). Integration of Children with Special Needs In Mathematics Through Virtual Reality. 8.

Kurz, B., \& Kubek, D. (2021). Kursbuch Wirkung Das Praxishandbuch für alle, die Gutes besser tun wollen.

Lannen, T., Brown, D., \& Powell, H. (2002). Control of virtual environments for young people with learning difficulties. Disability and Rehabilitation, 24(11-12), 578-586. https://doi.org/10.1080/09638280110111342

New learning concepts for schools. (2021). https://neuelehrkonzepte.ch/?p=146

Parsons, S. (2000). Development of social skills amongst adults with Asperger's Syndrome using virtual environments. Virtual Reality, 9.

Parsons, S., \& Cobb, S. (2011). State-of-the-art of virtual reality technologies for children on the autism spectrum. 13.

Self, T., Scudder, R. R., Weheba, G., \& Crumrine, D. (2007). A Virtual Approach to Teaching Safety Skills to Children With Autism Spectrum Disorder. Topics in Language Disorders, 27(3), $242-253$. https://doi.org/10.1097/01.TLD.0000285358.33545.79

Simões, M., Bernardes, M., Barros, F., \& Castelo-Branco, M. (2018). Virtual travel training for autism spectrum disorder: Proof-of-concept interventional study. JMIR Serious Games, 6(1), e5.

Someren, M. W. van, Barnard, Y. F., \& Sandberg, J. A. C. (1994). The think aloud method: A practical guide to modelling cognitive processes. Academic Press.

Stiftung Vivala. (2021, May 28). https://www.vivala.ch/

VrSocial. (2018). https://dl.acm.org/doi/abs/10.1145/3173574.3173778

WHO. (n.d.). ICD-11-Mortality and Morbidity Statistics. Retrieved May 1, 2021, from https://icd.who.int/browse11/ 1-m/en\#/http\%3a\%2f\%2fid.who.int\%2ficd\%2fentity\%2f437815624

Wieczorrek, H. W., \& Mertens, P. (2011). Management von IT-Projekten. Springer Berlin Heidelberg. https://doi.org/10.1007/978-3-642-16127-8 